\title{
Effect of Sudden Water Pollution Accident on Water Quality of the Jinhua River
}

\author{
Tao Ding ${ }^{1, a}$, Chunyan Su ${ }^{1, b}$ and Xiaojian Pan ${ }^{1, c}$ \\ ${ }^{1}$ China Jiliang University, College of Quality \& Safety Engineering, China \\ am15068748415@163.com, bdingtaohz@163.com, 'c1529626393@qq.com
}

Keywords: Jinhua River; Sudden water pollution accident; CFD; Water quality assessment

Abstract. Sudden water pollution accidents have great harm to the ecological environment of human society. In recent years, the water pollution accident has been the main content of the environmental pollution accident in our country. It is very necessary to simulate and evaluate the impact of sudden water pollution accident on the river water quality. At present in the numerical simulation, Fluent, CFX and other CFD computing software has been more mature, in the simulation of complex field has achieved good results. In the field of water environment simulation, according to the previous research results, we can sum up a set of more mature experience. Regarding to the Jinhua River as an example, we analyze water pollution accident impact on water quality in different water flow rate and provide a reference for the establishment of emergency system for sudden water pollution accident.

\section{Introduction}

The sudden water pollution accident is caused by natural disasters or man-made accidents and it spread quickly in water within short time [1]. The sudden water pollution accident is diversity, sudden, diffusivity and long-term [2-3]. The Paper select the Jinhua River as the object of study [4]. The computing hydraulics (Computational Fluid Dynamics, CFD for short) is an application discipline which is crossed by the theory of Fluid mechanics, computer technology and numerical methods. Its basic idea is to replace the original continuous physical quantity in space domain and time domain by a series of very variable values. Building equations about the relation between the field variables on these discrete points through certain principles and ways. Then the researcher solve the algebraic equations to obtain the field variable approximation [5]. The general CFD software including CFX, Fluent, Phoenics, Star-CD, CF design and so on [6].

\section{Modeling Scheme for the Sudden Water Pollution Accident of the Jinhua River}

The Water Quality Status of the Jinhua River. According to the Environmental Protection Bureau in Jinhua city issued "Jinhua city water environmental bulletin 2013", the Jinhua River water quality status is shown in Table 1.

Selection of Pollutants. Through above analysis, the pollutants is chosen as $16 \%$ ammonium sulfate solution in room temperature, flow medium is regarded as the normal river.

The Establishment of Three-Dimensional model for the Jinhua River. We Find the Jinhua River watershed in the Mapinfo software shown in figure 1, the red line is for the section. Now we make an attempt to get the endpoint for the origin of coordinates, make the east (right) as the $\mathrm{x}$ axis positive direction, get the north direction (up) as the coordinate y axis positive direction.

Table 1.Jinhua River monitoring section and the status of water quality

\begin{tabular}{|c|c|c|c|c|}
\hline Area & River & Section name & Water Quality Classification & Major Pollution Indicators \\
\hline Jinhua city area & & Hepan Bridge & V & NH3-N \\
\hline Jinhua city area & Jinhua River & Wucheng Bridge & V & NH3-N \\
\hline Jinhua city area & & Shen Village & IV & NH3-N \\
\hline Lanxi city & & Feilong & IV & Tot-P \\
\hline
\end{tabular}




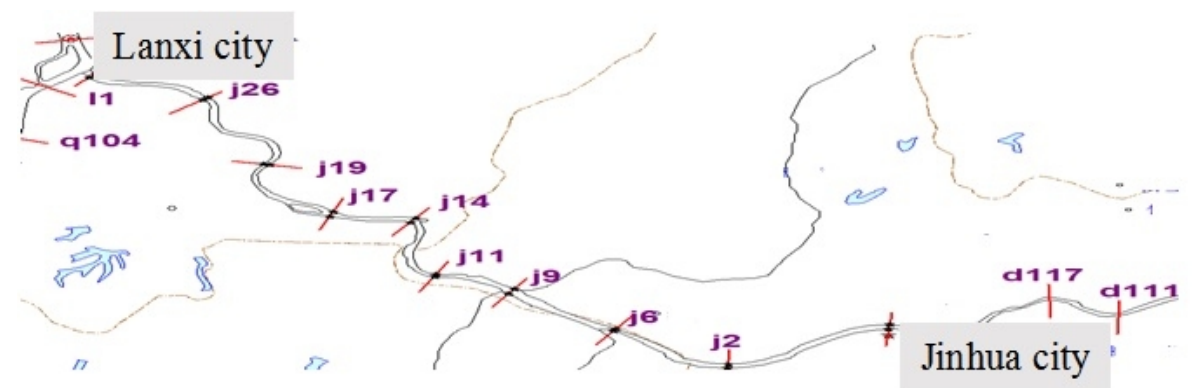

Figure 1. the section of the Jinhua River

The Jinhua River bed model is set up by following steps: importing coordinate points, describing Riverbed Profile, establishing the source of pollution, region partition for the river, the generation of mesh, definition of boundary, outputing Grid File.

\section{The Analysis of Result for Model Calculation}

the Solving Calculation of Fluent. The solution of the model mainly including defining the solver, defining the turbulence model, defining the transport model of components, defining the fluid, programing the UDF function, setting the gravity,defining the boundary condition, and setting the concentration monitoring. Finally,we do the impact analysis of variable for environment. We save calculation results and changing the water flow velocity after residual convergence,repeat the above process.

The affected degree analysis of different monitoring sites. When the water velocity is $2 \mathrm{~m} / \mathrm{s}$, the pollutant emission rate is $2 \mathrm{~m} / \mathrm{s}$, the discharge duration is $900 \mathrm{~s}$, the nitrogen concentration curve of each observation point is shown in Figure 8-10. The yellow line is the standard for ammonia nitrogen of water quality.

From figure 8-10, when pollution happens at the north bank of the river, monitoring point near the north shore is greater affected than the monitoring point than is away from the north. We compare the monitoring point in downstream with the upstream, the rising of speed is slow when the pollutant concentration arrives, but the total impact time is longer, the pollutant concentration peak is bigger and more serious. For the three spots in upstream , the pollutant concentration of monitoring point1-1 will increase dramatically in a short time on the north bank after the pollutants arrived.The point1-2 and point1-3 that are away from the north bank affected by pollution is light. For the three points in midstream and downstream,the rising speed is much slower than the upstream after pollutants reaching, but the total impact time is 1.5-2 times longer than upstream, pollutant concentration peak is far greater than the monitoring point in upstream.

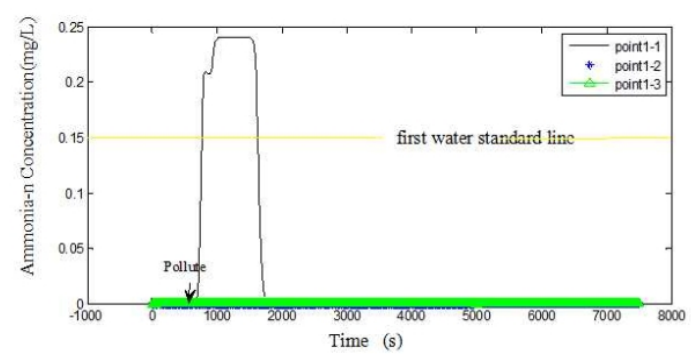

Figure 2.The ammonia nitrogen content curves of three monitoring sites in upstream 


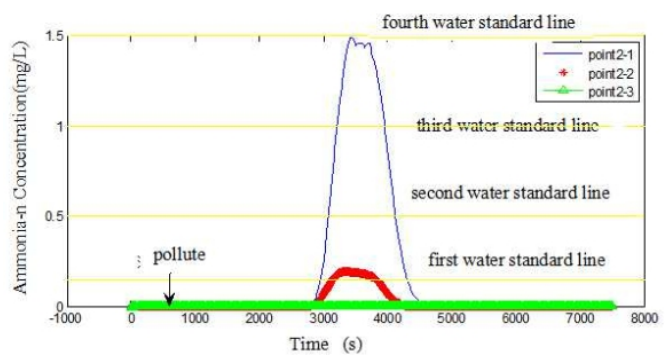

Figure 3.The ammonia nitrogen content curves of three monitoring sites in midstream

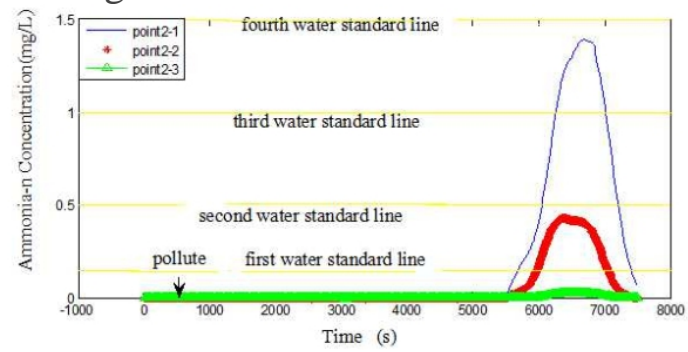

Figure 4.The ammonia nitrogen content curves of three monitoring sites in downstream

The Analysis of Water Pollution Accident at Different Water Flow Rate. Respectively, we change the water flow velocity to $3 \mathrm{~m} / \mathrm{s}, 4 \mathrm{~m} / \mathrm{s}$, keep other conditions changeless, draw the ammonia nitrogen concentration curve of each observation point under different speed after repeated calculation, the results are shown in figure 11-13.

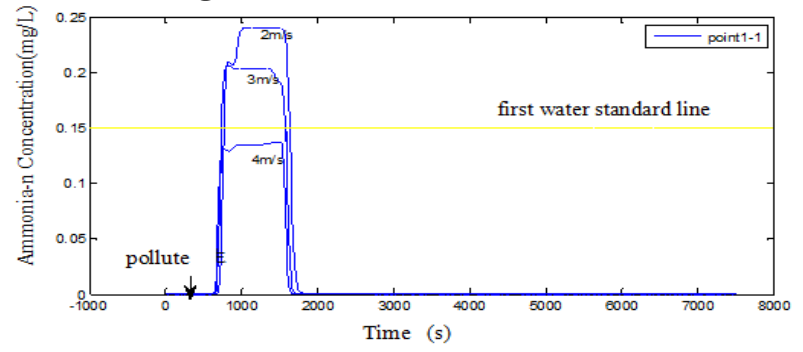

Figure 5.The ammonia nitrogen content curves of upstream monitoring sites at different water flow rate

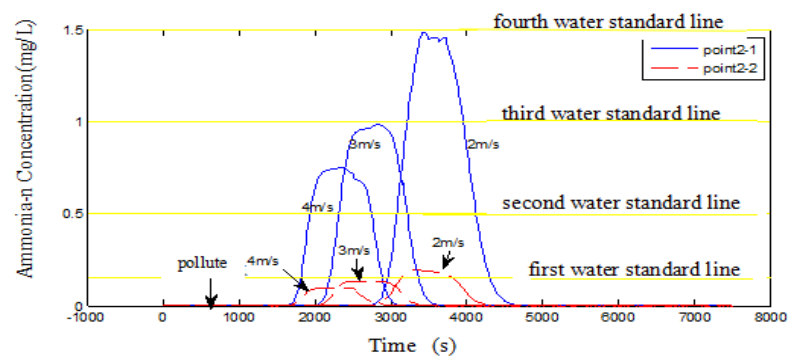

Figure 6.The ammonia nitrogen content curves of midstream monitoring sites at different water flow rate

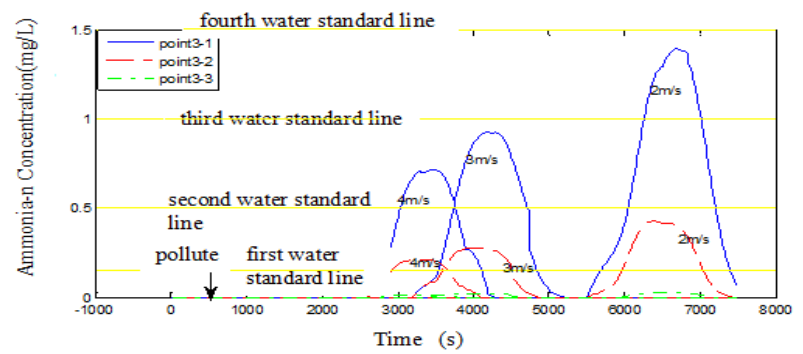

Figure 7.The ammonia nitrogen content curves of downstream monitoring sites at different water flow rate

From figure11-13, it can be concluded when the velocity grows, the time that the pollutant arrives monitoring shortens, but the total impact time and pollutant concentration peak will be reduce.For the monitoring station point $1-1$ in the upstream, when the speed increase from $2 \mathrm{~m} / \mathrm{s}$ to $4 \mathrm{~m} / \mathrm{s}$, the change for the arrival time and total affect time of pollutants seems not to be obvious, but the ammonia 
nitrogen concentration peak decreases greatly. For the observation points in the midstream and downstream, the change of arrival time and total affect time for pollutants is more obvious. With the increase of the velocity, the time of arrival for pollutants significantly ahead,the total impact time shortens, ammonia nitrogen concentration peak decline.

\section{Conclusions}

Through the analysis of simulation results, we get the following conclusion generally : (1) When the sudden pollution accident happens on one side of the river,the area which is at the same side with the pollution source and is closer to pollution source will be affected violently in a short time.But this effect is not long, with water dilutes and goes on constantly, the impact will be relieved fast after pollution sources stopping to discharge pollution. (2)The area where is far to the pollution sources in the downstream, pollutant is easy to deposit, the range of influence is wider, the peak concentration is bigger, the time of duration is longer. (3)For the influence of the computation time and computation performance, the simulation precision is not very high in this paper, the data is only revealed a general law. It would have a better result, if we do this study in a higher calculation accuracy.

\section{Acknowledgements}

This study was supported by Natural Science Foundation of Zhejiang Province (No. LY13E090005).

\section{References}

[1] Joyce Morrissey Donohue, John C. Lipscomb. Health advisory values for drinking water contaminants and the methodology for determining acute exposure values [J]. Science of the Total Environment. 2002 (1)

[2] The World Bank. Water Pollution Emergencies in China, Prevention and Response.

[3] Werner K., Graber. Real time modeling as an emergency support system for accidental release of air pollutants. Mathematics and Computer in Simulation.2000, 52:413-426

[4] The Jinhua River Spill China, December 2005, Field Mission Report, United Nations Environment Programme.

[5] Ender Demirel. Measured and simulated flow downstream of the submerged sluice gate [J]. Water and Environment Journal, 2015, 293

[6] Karl Pettersson, Arthur Rizzi. Comparing Different CFD Methods Accuracy in Computing Local Boundary Layer Properties [J]. Engineering Applications of Computational Fluid Mechanics, 2009, 31 